\title{
Performances of Homogeneous Charge Transfer Catalysts in the Electrocarboxylation of Benzyl Halides
}

\author{
Onofrio Scialdone, ${ }^{a}$ Giuseppe Filardo, ${ }^{*}, \mathrm{a}$ Alessandro Galia, ${ }^{a}$ Davide Mantione ${ }^{\mathrm{b}}$ \\ and Giuseppe Silvestri ${ }^{a}$
}

a Dipartimento di Ingegneria Chimica dei Processi e dei Materiali, Viale delle Scienze, 90128 Palermo, Italy and

bolvay S.A., Unità Ricerca Elettrolisi, Via Piave 6, 57013 Rosignano Solvay, Livorno, Italy

\begin{abstract}
Dedicated to Professor Henning Lund on the occasion of his 70th birthday.

Scialdone, O., Filardo, G., Galia, A., Mantione, D. and Silvestri, G., 1999.

Performances of Homogeneous Charge Transfer Catalysts in the Electrocarboxylation of Benzyl Halides. - Acta Chem. Scand. 53: 800-806. (C) Acta Chemica Scandinavica 1999.

The electrocarboxylation of benzyl halides to the corresponding carboxylic acids performed by homogeneous charge transfer catalysts is reported here. The performances of selected ester derivatives of benzoic acid and of the three isomers of benzenedicarboxylic acid as catalysts are evaluated on the basis of the faradaic efficiency of the carboxylation and of the decomposition rate of the catalyst. The standard redox potentials of catalysts are related to the selectivity of the process.

Rates of catalyst decomposition appear to be dependent on the molar ratio [halide]/[catalyst] and on the cathode material.
\end{abstract}

The electrocarboxylation of benzyl halides to the corresponding carboxylic acids has been the object, for several years, of significant attention because of its role in the synthesis of some 2-arylpropionic acids widely used as non-steroidal anti-inflammatory agents [eqn. (1)].

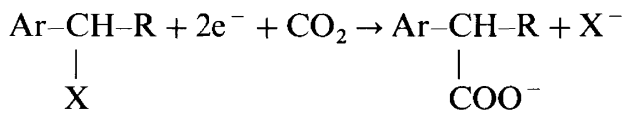

This synthetic route was first explored by Wawzonek ${ }^{1}$ in a two-compartment cell equipped with a mercury cathode; Baizer et al. $^{2}$ showed that the carboxylate anion is involved in an esterification, which consumes half of the starting halide.

The use of sacrificial anodes of aluminium ${ }^{3}$ or magnesium ${ }^{4}$ hinders the follow-up reaction inhibiting the nucleophilicity of the carboxylate anion, thus allowing the syntheses to be performed in undivided cells and very high yields of aluminium or magnesium salts of the acids to be obtained.

Attempts to scale up the process, ${ }^{5}$ in undivided cells equipped with stainless steel cathodes and magnesium sacrificial anodes, have shown the occurrence of an electrical passivation of the cathode surface. We report here that, in the case of benzylic chlorides, it is possible to hinder such passivation by the use of suitable homogeneous charge transfer catalysts (HCTC).

\footnotetext{
* To whom correspondence should be addressed.
}

The application of anion radicals as electron transfer reagents to the reduction of simple aromatic halides, carbon dioxide and activated olefins was widely investigated by Lund and Simonet. ${ }^{6-8}$

Later Vianello et al. ${ }^{9}$ have pointed out that it is possible to use, with good results, homogeneous catalysts (esters and nitriles) for the reduction of carbon dioxide, and Savéant ${ }^{10}$ has widely investigated the mechanism of charge transfer between several mediators and benzylic halides. The results reported here refer to the use of some homogeneous charge transfer catalysts in the presence of both benzylic halides and carbon dioxide.

\section{Results and discussion}

Early synthetic experiments. Figure 1 shows the variations of the cell current with time for the direct electroreduction of 1-(4-isobutylphenyl)-1-chloroethane (curve a) and for the same process catalysed by benzonitrile (curve b). In the direct reduction the current decreases rapidly from the beginning of the electrolysis while in the catalytic one the current intensity remains high for the whole synthesis. Our results are consistent with literature data previously quoted ${ }^{5}$ confirming that, in the presence of an aluminium anode, a strong decrease of the conductivity also occurs in the first stages of the electrolysis.

These results prompted us to investigate in greater detail the behaviour of electrolytic systems based on 


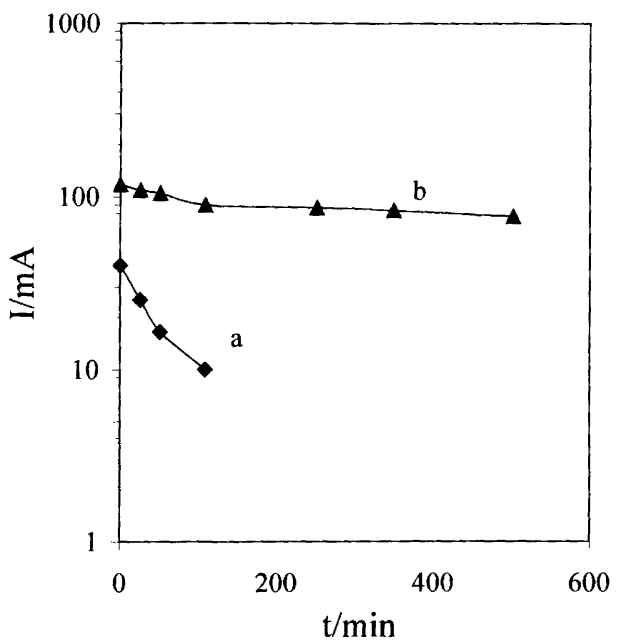

Fig. 1. Plot of current intensity vs. time for the electrocarboxylation of 1-(4-isobutylphenyl)-1-chloroethane performed in an undivided filter-press electrolytic flow cell. System solvent supporting electrolyte (SSE): $200 \mathrm{ml}$ DMF $0.1 \mathrm{M}$ $\mathrm{Bu}_{4} \mathrm{NBr}$. Reference electrode $\mathrm{Ag} / \mathrm{Agl} / \mathrm{I}^{-} 0.1 \mathrm{M}$ in DMF; cathode: compact graphite; anode, aluminium; electrode surface area $10 \mathrm{~cm}^{2}$. Electrolytic solution saturated with $\mathrm{CO}_{2}$ at $P=1 \mathrm{~atm}, T=25^{\circ} \mathrm{C}$, syntheses performed under constant cathodic potential condition. (a) Direct process, cathodic potential $-2.1 \mathrm{~V}$ vs. ref., initial halide concentration $0.05 \mathrm{M}$. (b) Process mediated by benzonitrile $(0.03 \mathrm{M})$, initial halide concentration $0.2 \mathrm{M}$, cathodic potential $-1.9 \mathrm{~V}$ vs. ref.

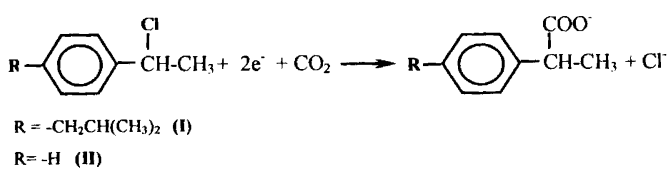

homogeneous charge transfer catalysts for the carboxylation of 1-(4-isobutylphenyl)-1-chloroethane (I) or 1-phenyl-1-chloroethane (II) [eqn. (2)]. In the further development of our investigation various benzoic and phthalic acid ester derivatives, chosen for their lower toxicity with respect to benzonitrile, were used as HCTC.

Cyclovoltammetric data. In Table 1 values of reduction peak potential $\left(E_{\mathrm{p}}\right)$ of some catalysts are compared with $E_{\mathrm{p}}$ of the halides. The cyclovoltammetric data are consistent with a catalytic electron transfer process when the esters listed in Table 1 are in the presence of halides or carbon dioxide.

In order to enhance the selectivity of the carboxylation reaction we have investigated the influence of the standard redox potential of the catalyst $\left(E_{\text {cat }}^{\circ}\right)$ on the competition between the homogeneous electron transfer reactions to carbon dioxide and benzylic halides. For an outersphere process it is possible to consider the charge transfer reaction as being composed of three successive steps:

$$
\begin{aligned}
\mathrm{Cat}^{\cdot-}+\mathrm{A} & \underset{k_{\mathrm{dif}}}{\stackrel{k_{\mathrm{dif}}}{\rightleftarrows}}\left(\mathrm{Cat}^{\cdot-}, \mathrm{A}\right) \underset{k_{2 \mathrm{act}}}{\stackrel{k_{1} \text { act }}{\leftrightarrows}}\left(\mathrm{Cat}, \mathrm{A}^{\cdot-}\right) \\
& \stackrel{k_{\mathrm{dir}}}{\stackrel{k_{\mathrm{dif}}}{\rightleftarrows}} \mathrm{Cat}+\mathrm{A}^{\cdot-}
\end{aligned}
$$

$\left(\mathrm{Cat}^{\cdot-}, \mathrm{A}\right)$ and $\left(\mathrm{Cat}, \mathrm{A}^{--}\right)$: reactants in their reaction sites; $\mathrm{Cat}^{--}+\mathrm{A}$ and $\mathrm{Cat}+\mathrm{A}^{--}$: reactants beyond the average diffusion distance; $k_{\text {dif }}$ diffusion-limited rate constant; $k_{1 \text { act }}$ and $k_{2 \text { act }}$ activation-controlled rate constants.

If the potential of the catalyst is not too far from the $E^{\circ}$, the Brønsted coefficient $\beta$ is close to 0.5 and two zones of diffusion control with 0 and $-1 / 58 \mathrm{mV}$ slopes, respectively, and an intermediate zone of activation control with $-1 / 116 \mathrm{mV}$ slope are expected in the $\log k_{1}$ vs. $E_{\text {cat }}^{\circ}$ plots $^{11}$ as shown in Fig. 2.

In the case of carbon dioxide Vianello et al. ${ }^{9}$ have questioned the outer sphere mechanism and have proposed a reaction pathway involving the formation of a bond between the anion radical of the catalyst and carbon dioxide. Those researchers pointed out that $\log k$ varies with $E_{\text {cat }}^{\circ}$ by ca. $-1 / 60 \mathrm{mV}$ for esters reducing between -1.91 and $-2.10 \mathrm{~V}$ vs. SCE and by ca. $-1 / 120 \mathrm{mV}$ for those reducing between -2.21 and $-2.31 \mathrm{~V}$ vs. SCE, as expected for a simple outer sphere reaction where the symmetry factor is close to 0.5 .

$$
\begin{aligned}
& \mathrm{Cat}^{\cdot-}+\mathrm{RCl} \stackrel{k}{\longrightarrow} \mathrm{Cat}+\mathrm{R}^{\cdot}+\mathrm{Cl}^{-} \\
& \mathrm{Cat}^{-}+\mathrm{RCl} \rightleftarrows \mathrm{Cat}+\mathrm{RCl}^{-}
\end{aligned}
$$

$\mathrm{RCl}$, organic halide; Cat, catalyst.

The reduction of 1-(4-isobutylphenyl)-1-chloroethane and 1-phenyl-1-chloroethane could occur with a concerted electron transfer-bond breaking mechanism

Table 1. Cyclovoltammetric data of the catalysts and of the substrate. ${ }^{a}$

\begin{tabular}{lll}
\hline Compound & $E^{\circ} / \mathrm{V}$ vs. ref. & $i_{\text {sub }}^{\text {p }} / 2 \gamma i_{\mathrm{d}}^{\mathrm{p}}$ \\
\hline Benzenecarboxylic acid phenyl ester & -2.02 & 1.18 \\
1,2-Benzenedicarboxylic acid dibutyl ester & -1.95 & 0.80 \\
1,3-Benzenedicarboxylic acid dimethyl ester & -1.90 & 0.72 \\
1,4-Benzenedicarboxylic acid dimethyl ester & -1.62 & 0.53 \\
1-(4-Isobutylphenyl)-1-chloroethane & $-0.6 /-0.9^{b}$ & \\
1-phenyl-1-chloroethane & $-0.6 /-0.9^{b}$ & \\
\hline
\end{tabular}

${ }^{a}$ System solvent supporting electrolyte (SSE): $30 \mathrm{ml} \mathrm{DMF} 0.1 \mathrm{M} \mathrm{Bu} 4 \mathrm{NBr}$. Reference electrode: $\mathrm{Ag} / \mathrm{Agl} / \mathrm{I}^{-} 0.1 \mathrm{M}$ in DMF; working electrode Pt disk $3.14 \mathrm{~mm}^{2}$; scan rate $0.1 \mathrm{~V} \mathrm{~s}^{-1}$. Catalyst concentration: $5 \mathrm{mM}$; 1-(4-isobutylphenyl)-1-chloroethane concentration: $10 \mathrm{mM}$. $I_{\text {sub }}^{\mathrm{p}}$ : catalytic peak current intensity in the presence of 1 -(4-isobutylphenyl)-1-chloroethane; $I_{\mathrm{d}}^{\mathrm{p}}$ : peak current intensity of the catalyst; $\gamma=$ [halide]/[catalyst] (excess factor). ${ }^{b}$ Estimated by group contribution rule. ${ }^{12}$ 


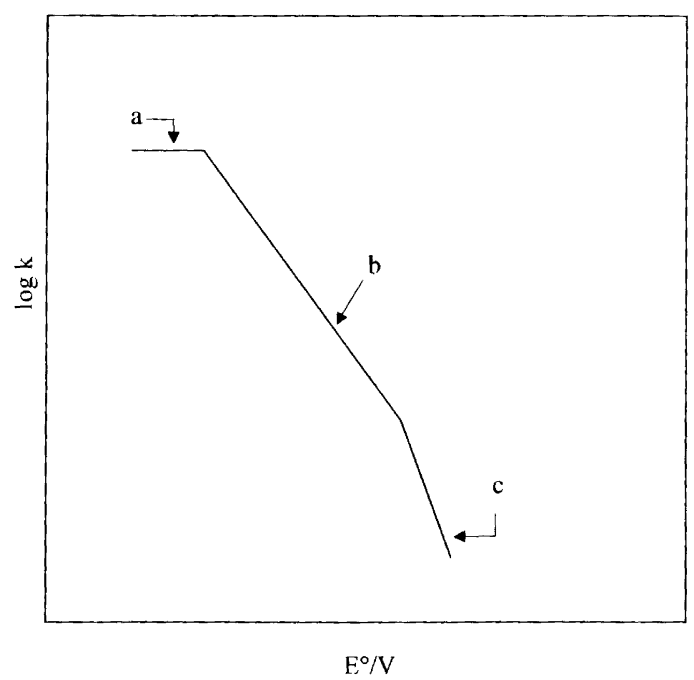

Fig. 2. Theoretical variations of the homogeneous forward electron transfer rate constant with standard redox potential. (a) Diffusion control of reagents: $\log k_{1}=\log k_{\text {dif }}$. (b) Activation control: $\log k_{1}=\log k_{\mathrm{s}}^{\text {sol }}-\beta\left(E_{\text {cat }}^{\circ}-E^{\circ}\right) / 0.058$. (c) Diffusion control of products: $\log k_{1}=$ $\log k_{\text {dif }}-\left(E_{\text {cat }}^{\circ}-E^{\circ}\right) / 0.058$.

[eqn. (3)] or through the intermediacy of the anion radical [eqn. (4)].

Savéant et al. established the stepwise character of the reductive cleavage in aryl halides ${ }^{11}$ and its concerted character in the case of aliphatic halides. ${ }^{12}$ Those authors observed that the reduction of benzyl chloride occurs via a concerted electron transfer-bond breaking mechanism while the reduction of nitro-substituted benzyl chlorides involves the formation of the anion radical as an intermediate; when slightly less electron-withdrawing substituents were involved the reaction occurred via a concerted mechanism. ${ }^{13}$ In the case of 1-phenyl-1-chloroethane, good agreement was observed between the experimental data and the predictions of the theory of the dissociative electron transfer. ${ }^{10}$

For 1-(4-isobutylphenyl)-1-chloroethane the presence of an electron-donating substituent led us to suppose that a concerted mechanism is involved; for this compound our cyclovoltammetric data show that the transfer coefficient $\alpha$, derived ${ }^{13,14}$ from $E_{\mathrm{p}}$ vs. $\log v$ ( $v$ is the scan rate), has a value distinctly lower than 0.5 (ca. 0.3 ).

In the case of 1-(4-isobutylphenyl)-1-chloroethane the standard redox potential of the couple ArCHXR/ $\mathrm{ArCHR}{ }^{\circ}+\mathrm{X}^{-}$was estimated, by the group contribution rule, ${ }^{12}$ to be in the range -0.6 to $-0.9 \mathrm{~V}$ vs. SCE. On the other hand $E^{\circ}$ of the couple ArCHXR/ArCHXR ${ }^{\circ}$ can be estimated to be at most $100 \mathrm{mV}$ more positive than that of the $\mathrm{ArCH}_{2} \mathrm{R} / \mathrm{ArCH}_{2} \mathrm{R}^{\cdot-}$ couple. ${ }^{13}$ In cyclovoltammetric experiments performed at $0.1 \mathrm{~V} \mathrm{~s}^{-1}$ with 1-(4-isobutylphenyl)-1-chloroethane, the wave corresponding to the $\mathrm{ArCH}_{2} \mathrm{R}$ reduction was not observed before the involvement of the electrolytic medium, indicating that $E^{\circ}$ of the couple $\operatorname{ArCHXR} / \mathrm{ArCHXR}{ }^{-}$is at least $0.6 \mathrm{~V}$ more negative than the reductive cleavage peak potential.

As reported by Savéant for similar benzyl halides ${ }^{13}$ these results are consistent with the hypothesis of an electron transfer to the substrate concerted with the cleavage of the carbon-halogen bond.

According to the literature ${ }^{13,15}$ we have computed $\log k$ of the forward electron transfer reaction from several catalysts to our substrate: the catalytic activity results in an enhancement of the cathodic peak of the catalyst compared with that observed in the absence of the halide. This 'catalytic effect' is a function of $k$ in the case where the forward homogeneous electron transfer is the rate-determining step. It can therefore be used to determine $k$ from an appropriate treatment of the kinetic data of these reactions.

The values of $\log k$ plotted as a function of $E_{\text {cat }}^{\circ}$ in Fig. 3 show that the Brønsted coefficient $\beta$ value is significantly lower than 0.5 (ca. 0.27) (average slope of $\log k$ vs. $E_{\text {cat }}^{\circ}$ ca. $-1 / 200 \mathrm{mV}$ ), and it is not possible to determine a range of potential where the electron transfer reaction is under diffusion control of $\mathrm{RX}^{-}$.

This result fits the hypothesis that a concerted mechanism is involved and consequently that the standard redox potential is much more positive than $E_{\text {cat }}^{\circ}$ of the catalysts tested.

As the average slope of $\log k$ vs. $E_{\text {cat }}^{\circ}$ for our ester derivative catalysts is ca. $-1 / 200 \mathrm{mV}$ for 1 -(4-isobutylphenyl)-1-chloroethane and between $-1 / 60 \mathrm{mV}$ and $-1 / 120 \mathrm{mV}$ for $\mathrm{CO}_{2}$, the homogeneous forward electron

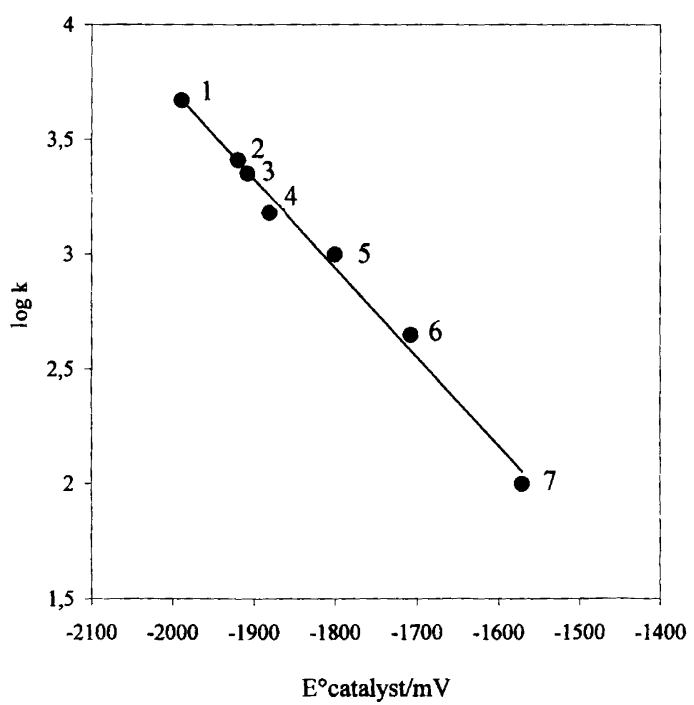

Fig. 3. Variation of the rate constant of electron transfer between 1-(4-isobutylpheny)-1-chloroethane and different compounds as HCTCs: effect of the standard redox potential of the catalyst. System solvent supporting electrolyte (SSE): NMP $0.1 \mathrm{M} \mathrm{Bu} \mathrm{N}_{4} \mathrm{NBr}$. Selected compounds: $1=$ benzenecarboxylic acid phenyl ester; 2=1,2-benzenedicarboxylic acid dibutyl ester; $3=1,2$-benzenedicarboxylic acid dimethyl ester; $4=1,3$-benzenedicarboxylic acid dimethyl ester; $5=$ 9,10-diphenylanthracene; $6=1,2$-benzacenaphthene; $7=$ acenaphthene. 
transfer rate constant increases with $E_{\text {cat }}^{\circ}$ more rapidly for $\mathrm{CO}_{2}$ than for our substrate.

On this basis we looked for catalysts that reduce at less negative potentials in order to minimise the reduction of carbon dioxide.

Similar considerations can be extended to the electrosyntheses involving 1-chloro-1-phenylethane, as it is known in literature ${ }^{10}$ that this halide is reduced by a concerted mechanism and the standard potential of the $\mathrm{ArCHXCH} / \mathrm{ArCHCH}_{3}{ }^{+}+\mathrm{X}^{-}$couple falls within the range of -0.6 to $-0.9 \mathrm{~V}$ vs. SCE, thus indicating a Brønsted coefficient $\beta$ value significantly lower than 0.5 for our catalysts.

Synthetic performance. A set of potentiostatic electrolyses performed with different HCTCs was carried out to determine the influence of the $E_{\text {cat }}^{\circ}$ on the electrocarboxylation of 1-(4-isobutylphenyl)-1-chloroethane (Table 2). According to previous considerations syntheses performed with catalysts that are reduced at more negative potentials give lower faradaic efficiencies. In the case of 1,4-benzenedicarboxylic acid dimethyl ester, which is reduced at a less negative potential, fast decomposition of the catalyst was observed. Between 1,2-benzenedicarboxylic acid dibutyl ester and 1,3-benzenedicarboxylic acid dimethyl ester, whose performances are better, the latter, showing lower toxicity, ${ }^{16}$ was chosen for further investigation. The same dependence of faradaic yields vs. $E_{\text {cat }}^{\circ}$ has been observed for the electrocarboxylation of 1-phenyl-1-chloroethane (Table 3). For both the halides oxalate anion is the main by-product. Other identified by-products are 1-ethyl-4-isobutylbenzene and 1-vinyl-4-isobutylbenzene for the electrocarboxylation of 1-(4-isobutylphenyl)1-chloroethane, and ethylbenzene and vinylbenzene for the electrolysis of 1-phenyl-1-chloroethane.

Figures 4 and 5 show the variations of the concentrations of 1-(4-isobutylphenyl)-1-chloroethane, 2-(4-isobutylphenyl)propionic acid (carboxylate) and 1,3-benzenedicarboxylic acid dimethyl ester with charge passed. In the first stages of the electrolysis the catalyst is consumed at a very reduced rate (ca. $3.6 \times 10^{-3}$ moles per faraday passed), but as the excess factor $\gamma=$ [halide]/[catalyst] decreases below a critical value $\left(\gamma^{*}\right)$ roughly estimated as 30-35, the curve of Fig. 5 undergoes a dramatic change of slope (point $\mathrm{a}^{*}$ ), and the catalyst decomposes at a much higher rate (ca. $3.3 \times 10^{-2}$ moles per faraday passed). This behaviour is not affected by the initial concentration of halide and catalyst but by their ratio, the critical value of which depends on the substratecatalyst couple (Table 4). Moreover we have observed that, for a given substrate, the lower the $E^{\circ}$ the higher the $\gamma^{*}$ value.

Syntheses performed with stepwise substrate additions confirmed that the consumption of the catalyst is moderate provided that $\gamma$ is higher than the critical value $\gamma^{*}$ during the entire electrosynthesis. Similar values of faradic efficiencies and of catalyst decomposition rates were obtained using both 1-methyl-2-pyrrolidinone (NMP) or $N, N$-dimethylformamide (DMF).

Influence of the cathode material. Besides the excess factor value, the nature of the cathode also strongly affects the decomposition rate of the catalyst. As shown in Fig. 6(a) and $6(\mathrm{~b})$ the value of $\gamma^{*}$ does not depend on the cathode material (compact graphite, $\mathrm{Pt}$ and $\mathrm{Cu}$ ) thus suggesting that for $\gamma<\gamma^{*}$ a fast homogeneous decomposition of the catalyst could be involved. When the excess factor is higher than its critical value the decomposition rate of the catalyst seems to be dependent mainly on the cathode material [Fig. 6(a)]. In the case of zinc and lead the decomposition rate at the beginning of the synthesis is so high that it is not possible to observe a change in the slope. Syntheses performed with platinum are characterised by a strong decrease in the current from the early stages of the electrolysis.

It seems reasonable, according to these results, to suppose that the decomposition of the catalyst takes place both on the cathode surface and in the homogeneous phase, the latter becoming moderate for high values of the molar ratio [halide]/[catalyst]. As shown in Table 5 compact graphite gives better results concerning the decomposition of the catalyst.

Table 2. Electrocarboxylation of 1-(4-isobutylphenyl)-1-chloroethane with different catalysts. ${ }^{a}$

\begin{tabular}{llll}
\hline Catalyst & $E_{\text {cat }}^{\circ} /$ vs. SCE & $\begin{array}{l}\text { Carboxylate faradaic } \\
\text { yield (\%) }\end{array}$ & Charge passed/F mol $^{-1}$ \\
\hline Benzonitrile & -2.26 & 60.0 & 2.59 \\
Benzenecarboxylic acid methyl ester & -2.20 & 64.5 & 2.59 \\
Benzenecarboxylic acid phenyl ester & -2.02 & 62.0 & 2.59 \\
1,2-Benzenedicarboxylic acid dibutyl ester & -1.95 & 80.4 & 2.28 \\
1,3-Benzenedicarboxylic acid dimethyl ester & -1.90 & 76.0 & 2.28 \\
1,4-Benzenedicarboxylic acid dimethyl ester & -1.62 & 44.0 & 1.86 \\
\hline
\end{tabular}

a Potentiostatic electrolyses performed in undivided tank cells with a parallel plate electrode arrangement, reference electrode $\mathrm{Ag} / \mathrm{Agl} / \mathrm{I}^{-} 0.1 \mathrm{M}$ in DMF, cathode compact graphite, anode aluminium, electrode surface area $12 \mathrm{~cm}^{2}$, working cathodic potential $E_{\mathrm{c}}$ determined by polarisation curves for each catalyst. System solvent supporting electrolyte (SSE): $50 \mathrm{ml} \mathrm{NMP}$ $0.1 \mathrm{M} \mathrm{Bu}_{4} \mathrm{NBr}$, initial catalyst concentration $5 \mathrm{mM}$, starting halide concentration $0.2 \mathrm{M}$. Electrolytic solution saturated with $\mathrm{CO}_{2}$ at $P=1 \mathrm{~atm}, T=25^{\circ} \mathrm{C}$. ${ }^{b}$ Evaluated according to eqn. (2) for compound $\mathrm{I}$. 
Table 3. Electrocarboxylation of 1-phenyl-1-chloroethane with different catalysts. ${ }^{a}$

\begin{tabular}{llll}
\hline Catalyst & $E_{\text {cat }}^{\circ} /$ Vs. SCE & $\begin{array}{l}\text { Carboxylate faradaic } \\
\text { yield }(\%)^{b}\end{array}$ & ${\text { Charge passed } / \mathrm{F} \mathrm{mol}^{-1}}^{\text {Benzenecarboxylic acid methyl ester }}$ \\
\hline Benzenecarboxylic acid phenyl ester & -2.20 & 57.0 & 2.59 \\
1,3-Benzenedicarboxylic acid dimethyl ester & -2.02 & 85.0 & 2.38 \\
\hline
\end{tabular}

${ }^{a}$ Potentiostatic electrolyses performed in undivided tank cells with a parallel plate electrode arrangement, reference electrode $\mathrm{Ag} / \mathrm{Agl} / \mathrm{I}^{-} 0.1 \mathrm{M}$ in DMF, cathode compact graphite, anode aluminium, electrode surface area $12 \mathrm{~cm}^{2}$, cathodic potential $E_{\mathrm{c}}$ determined by polarisation curves for each catalyst. System solvent supporting electrolyte (SSE): $50 \mathrm{ml} \mathrm{NMP} 0.1 \mathrm{M} \mathrm{Bu} \mathrm{NBr}_{4}$, initial catalyst concentration $5 \mathrm{mM}$, starting halide concentration $0.2 \mathrm{M}$. Electrolytic solution saturated with $\mathrm{CO}_{2}$ at $P=1$ atm, $T=25^{\circ} \mathrm{C} .{ }^{b}$ Evaluated according to eqn. (2) for compound II.

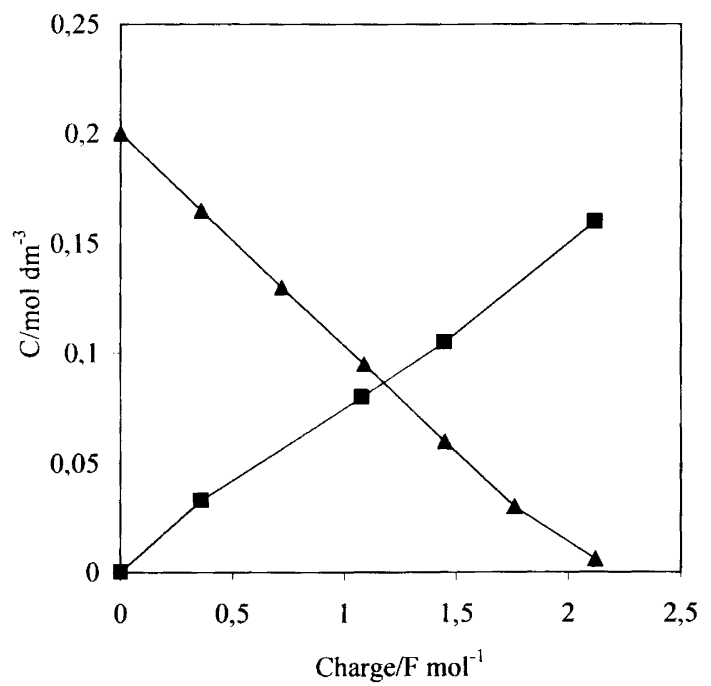

Fig. 4. Concentration of 1-(4-isobutylphenyl)-1-chloroethane $(\boldsymbol{\Delta})$ and of 2-(4-isobutylphenyl)propionic acid (carboxylate) ( $\square$ ) as a function of the charge passed ( $\mathrm{F} \mathrm{mol}^{-1}$ calculated on the amount of substrate involved). Undivided tank cell with a parallel plate electrode arrangement, reference electrode $\mathrm{Ag} / \mathrm{Agl} / \mathrm{I}^{-} 0.1 \mathrm{M}$ in DMF, cathode compact graphite, anode aluminium, electrode surface area $12 \mathrm{~cm}^{2}$. Potentiostatic electrolysis: cathodic potential $-1.6 \mathrm{~V}$ vs. ref. System solvent supporting electrolyte (SSE): $50 \mathrm{ml}$ NMP $0.1 \mathrm{M} \mathrm{Bu}_{4} \mathrm{NBr}$, starting halide concentration $0.2 \mathrm{M}$, initial catalyst concentration (1,3-benzenedicarboxylic acid dimethyl ester) $5 \mathrm{mM}$. Electrolytic solution saturated with $\mathrm{CO}_{2}$ at $P=$ $1 \mathrm{~atm}, T=25^{\circ} \mathrm{C}$

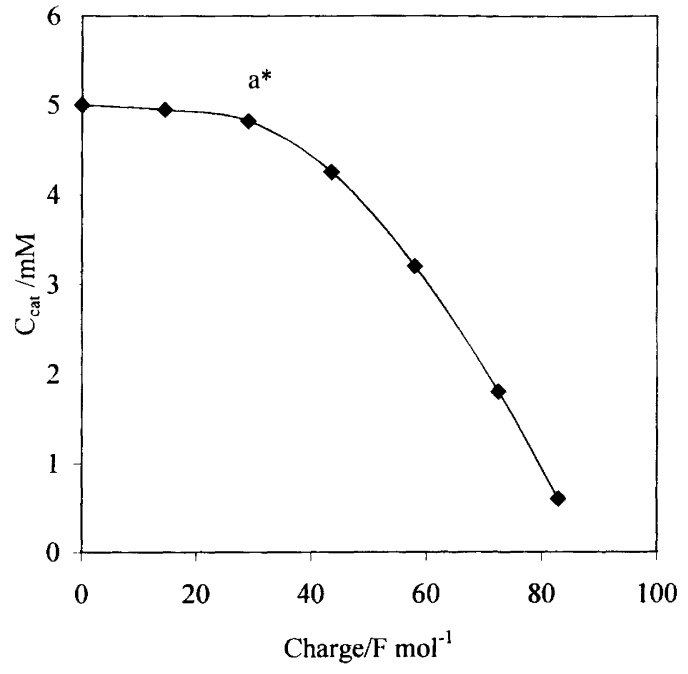

Fig. 5. Variation of the concentration of 1,3-benzenedicarboxylic acid dimethyl ester with charge passed ( $\mathrm{F} \mathrm{mol}{ }^{-1}$ calculated on the amount of catalyst involved). Potentiostatic electrolyses performed in undivided tank cells with a parallel plate electrode arrangement, reference electrode $\mathrm{Ag} / \mathrm{Agl} / \mathrm{I}^{-} 0.1 \mathrm{M}$ in DMF, cathode compact graphite, anode aluminium, electrode surface area $12 \mathrm{~cm}^{2}$, cathodic potential $-1.6 \mathrm{~V}$ vs. ref. System solvent supporting electrolyte (SSE): $50 \mathrm{ml} \mathrm{NMP} 0.1 \mathrm{M} \mathrm{Bu}_{4} \mathrm{NBr}$, starting halide concentration $0.2 \mathrm{M}$, initial catalyst concentration $5 \mathrm{mM}$. Electrolytic solution saturated with $\mathrm{CO}_{2}$ at $P=1 \mathrm{~atm}, T=25^{\circ} \mathrm{C}$.

Table 4. Critical value $\gamma^{*}$ of the excess factor [halide]/[catalyst] for different substrate-catalyst couples. ${ }^{a}$

\begin{tabular}{llll}
\hline Catalyst & $E^{\circ} /$ vs. SCE & Substrate & $\gamma^{*}$ \\
\hline 1,3-Benzenedicarboxylic acid dimethyl ester & -1.41 & $1-(4-$-sobutylphenyl)-1-chloroethane & $30-35$ \\
1,2-Benzenedicarboxylic acid dibutyl ester & -1.45 & $1-(4-$ Isobutylphenyl)-1-chloroethane & $30-35$ \\
Benzenecarboxylic acid methyl ester & -1.68 & $1-(4-$ sobutylphenyl)-1-chloroethane & $50-55$ \\
1,3-Benzenedicarboxylic acid dimethyl ester & -1.41 & 1 -Phenyl-1-chloroethane & $25-30$ \\
Benzenecarboxylic acid phenyl ester & -1.57 & 1 1-Phenyl-1-chloroethane & $30-35$ \\
Benzenecarboxylic acid methyl ester & -1.68 & 1-Phenyl-1-chloroethane & $40-45$ \\
\hline
\end{tabular}

${ }^{a}$ Potentiostatic electrolyses performed in undivided tank cells with a parallel plate electrode arrangement, reference electrode $\mathrm{Ag} / \mathrm{Agl} / \mathrm{I}^{-} 0.1 \mathrm{M}$ in DMF, cathode compact graphite, anode aluminium, electrode surface area $12 \mathrm{~cm}^{2}$, cathodic potential $E_{\mathrm{c}}$ corresponding to the half-wave cathodic peak potentil of each catalyst. System solvent supporting electrolyte (SSE): $50 \mathrm{ml}$ NMP $0.1 \mathrm{M} \mathrm{Bu}_{4} \mathrm{NBr}, \gamma^{*}$ values obtained for each couple from a set of electrolyses performed with different initial concentrations of catalyst $(2,4,6,8 \mathrm{mM})$ and halide $(0.05,0.1,0.2,0.3 \mathrm{M})$. Electrolytic solution saturated with $\mathrm{CO}_{2}$ at $P=1 \mathrm{~atm}, T=25^{\circ} \mathrm{C}$. 

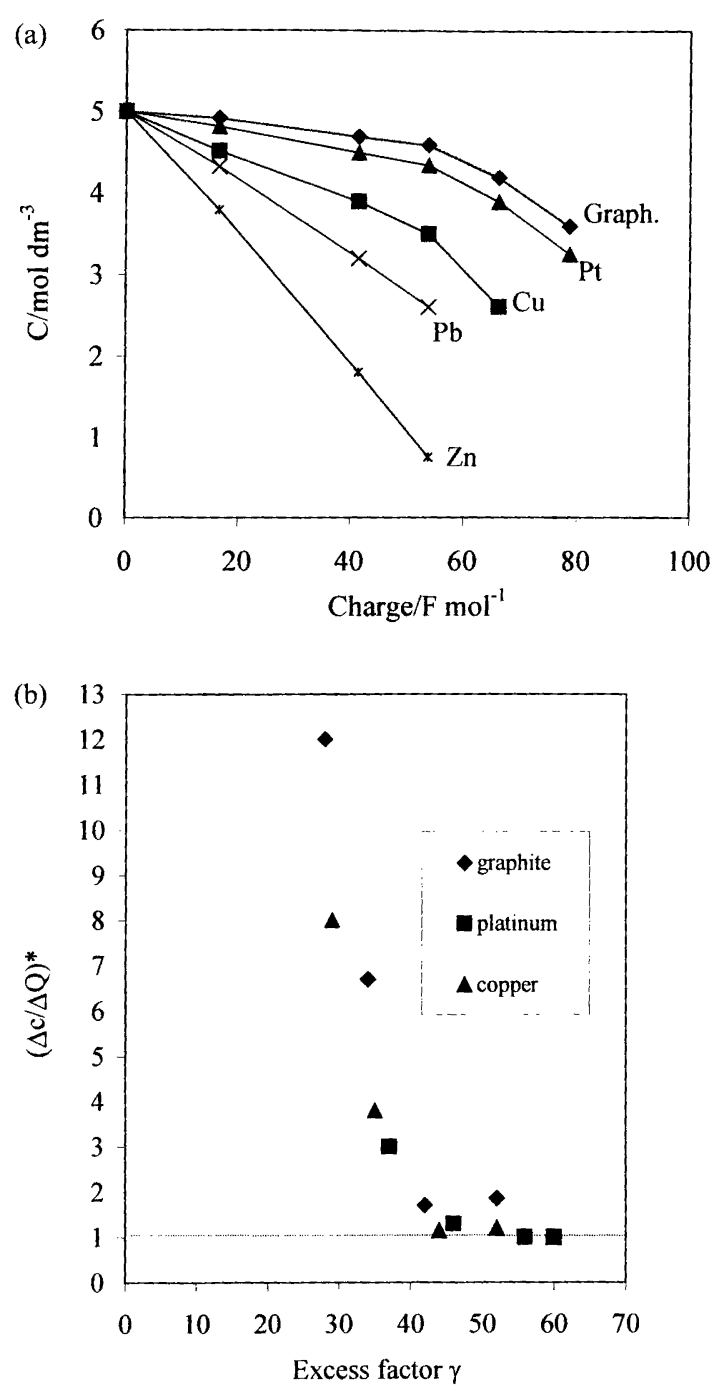

Fig. 6. (a) Variation of the concentration of 1,3-benzenedicarboxylic acid dimethyl ester with charge passed ( $\mathrm{F} \mathrm{mol}{ }^{-1}$ calculated on the amount of catalyst involved) for different cathodic materials. (b) Medium slope of the curve catalyst concentration vs. charge, relative to its initial value, as a function of the excess factor. $(\Delta C / \Delta Q)^{*}=$ $(\Delta C / \Delta Q)_{Q} /(\Delta C / \Delta Q)_{Q=0}$. Potentiostatic electrolyses performed in undivided tank cells with parallel plate electrode arrangement, reference electrode $\mathrm{Ag} / \mathrm{Agl} / \mathrm{I}^{-} 0.1 \mathrm{M}$ in $\mathrm{DMF}$, cathode compact graphite, anode aluminium, electrode surface area $12 \mathrm{~cm}^{2}$, cathodic potential $-1.6 \mathrm{~V}$ vs. ref. System solvent supporting electrolyte (SSE): $50 \mathrm{ml} \mathrm{NMP} 0.1 \mathrm{M} \mathrm{Bu}_{4} \mathrm{NBr}$, initial catalyst concentration $5 \mathrm{mM}$, starting excess factor $\gamma>36$. Electrolytic solution saturated with $\mathrm{CO}_{2}$ at $P=1 \mathrm{~atm}$, $T=25^{\circ} \mathrm{C}$.

Decomposition of the catalyst. Pletcher ${ }^{17}$ and Gul'tyai ${ }^{18}$ have reported that the reduction of benzenecarboxylic acid methyl ester in DMF leads quantitatively to benzoate anion through the first order reaction

$\mathrm{RCOOR}_{1}^{-} \rightarrow \mathrm{RCOO}^{-}+\mathrm{R}_{1}$.

Wagenknecht ${ }^{19}$ supposed that oxygen-alkyl bond cleavage is the major pathway of decomposition of benzoate ester radical anions in aprotic media. The main
Table 5. Influence of the cathode material on the consumption of the catalyst. ${ }^{a}$

\begin{tabular}{lc}
\hline Cathode & $\begin{array}{l}\text { Extent of catalyst } \\
\text { decomposition } / \mathrm{mmol} \mathrm{F}^{-1}\end{array}$ \\
\hline Graphite & 3.6 \\
Platinum & 4.5 \\
Copper & 14.0 \\
Lead & 19.8 \\
Zinc & 30.0 \\
\hline
\end{tabular}

${ }^{a}$ Potentiostatic electrolyses performed in undivided tank cells with a parallel plate electrode arrangement, reference electrode $\mathrm{Ag} / \mathrm{Agl} / \mathrm{I}^{-} 0.1 \mathrm{M}$ in DMF, cathode compact graphite, anode aluminium, electrode surface area $12 \mathrm{~cm}^{2}$, cathodic potential $-1.6 \mathrm{~V}$ vs. ref. System solvent supporting electrolyte (SSE): $50 \mathrm{ml} \mathrm{NMP} 0.1 \mathrm{M} \mathrm{Bu}_{4} \mathrm{NBr}$, initial catalyst concentration $5 \mathrm{mM}$, excess factor $\gamma>36$ during the entire electosynthesis. Electrolytic solution saturated with $\mathrm{CO}_{2}$ at $P=1 \mathrm{~atm}, T=25^{\circ} \mathrm{C}$.

product of decomposition of benzenacarboxylic acid methyl ester was found to be benzenecarboxylic acid, according to the literature. Phenol and benzaldehyde were found in the case of benzenecaboxylic acid phenyl ester resulting from cleavage of the ester bond, while for 1,3-benzenedicarboxylic acid dimethyl ester the presence of benzoic acid could be attributed to a cleavage of the ether bond followed by a decarboxylation process. No analytical evidence was found of direct catalyst carboxylation.

\section{Conclusions}

It has been shown that the use of homogeneous electron transfer catalysts in the electrocarboxylation of benzyl halides avoids the passivation phenomena observed in the case of direct reduction.

By appropriate choice of the standard redox potential of the catalyst it is possible to obtain high faradaic efficiencies $(75-80 \%)$ for the process of carboxylation and to minimise the formation of oxalate. Furthermore, it has been demonstrated that the catalyst is consumed at a very low rate, provided that the excess factor [halide]/[catalyst] is higher than a given threshold value, different for each halide-catalyst couple, and by the use of compact graphite as the cathode material.

\section{Experimental}

The electroanalytical experiments were carried out in $N, N$-dimethylformamide (DMF) with $0.1 \mathrm{M}$ tetrabutylammonium bromide $\left(\mathrm{Bu}_{4} \mathrm{NBr}\right)$ as the supporting electrolyte, a platinum disc as the working electrode (area $3.14 \mathrm{~mm}^{2}$ ), a platinum spiral as the counter electrode and $\mathrm{Ag} / \mathrm{AgI} / \mathrm{I}^{-} 0.1 \mathrm{M}$ in DMF as the reference electrode. The potential was scanned by means of an AMEL System 5000 potentiostat controlled through a PC.

Potentiostatic electrolyses were performed in undivided tank glass cells of planar geometry equipped with a gas 
inlet, an $\mathrm{Ag} / \mathrm{AgI} / \mathrm{I}^{-}$reference electrode, 99.99 aluminium sacrificial anode and different working electrodes (graphite, copper, zinc, platinum and lead).

Periodic analyses of the electrolytical solution were performed during the electrosyntheses on $2 \mathrm{~cm}^{3}$ samples drawn from the cell.

An Amel 533 potentiostat and 731 current integrator were used in all experiments. Aluminium electrodes (area $5 \mathrm{~cm}^{2}$ ) were treated with $20 \%$ aqueous hydrochloric acid, then carefully washed with distilled water, then with acetone and finally dried with nitrogen.

All working electrodes were mechanically polished prior to use; graphite electrodes were further treated by being heated to a red colour.

The solvents used were DMF or 1-methyl2-pyrrolidinone (NMP) both Anydroscan from Labscan (max. water content $100 \mathrm{ppm}$ ) and further dried over molecular sieves $4 \AA$. The ammonium salt $\mathrm{Bu}_{4} \mathrm{NBr}$ was crystallised from ethyl acetate. 1-(4-Isobutylphenyl)1-chloroethane was prepared by conventional FriedelCrafts acylation of isobutylbenzene in $\mathrm{CH}_{2} \mathrm{Cl}_{2}$ followed by hydrogenation with $\mathrm{NaBH}_{4}$ of the 1-(4-isobutylphenyl)ethanone to the corresponding alcohol and by the substitution of the $-\mathrm{OH}$ group with $-\mathrm{Cl}$ by an excess of conc. $\mathrm{HCl}$ using analytical grade reagents. The product structure was confirmed by NMR and GC-MS. 1-Phenyl-1-chloroethane was analytical grade from Aldrich.

Work-up of electrolytic solutions. After electrolysis the solvent was evaporated off under reduced pressure and the residue was acidified with aqueous hydrochloric acid and extracted with diethyl ether. After evaporation of the solvent it was possible to recover the raw carboxylic acid which was crystallised from ethanol.

Chromatographic analyses were performed with a Perkin-Elmer 410 LC, equipped with a Supelco LC8 column. Products structures were confirmed by GC--MS.
Acknowledgements. MURST and CNR are gratefully acknowledged for their financial support.

\section{References}

1. Wawzonek, S., Duty, R. C. and Wagenknecht, J. H. J. Electrochem. Soc. 111 (1964) 74.

2. Baizer, M. M. and Chruma, J. L. J. Org. Chem. 37 (1972) 1951.

3. Silvestri, G., Gambino, S., Filardo, G. and Gulotta, A. Angew Chem. 23 (1984) 979.

4. Sock, O., Troupel M. and Perichon, J. Tetrahedron Lett. $26(1985) 1509$.

5. Chaussard, J. In: Genders, J. D. and Pletcher, D., Eds., Electrosynthesis from Laboratory, to Pilot, to Production, The Electrosynthesis Company Inc., New York 1990, Chap. 8.

6. Lund, H. and Simonet, J. J. Electroanal. Chem. 65 (1975) 205.

7. Lund, H., Michel, M.-A. and Simonet, J. Acta Chem. Scand., Ser. B 28 (1974) 901.

8. Lund, H., Michel, M.-A. and Simonet J. Acta Chem. Scand., Ser. B 29 (1975) 231.

9. Gennaro, A., Isse, A. A., Savéant, J. M., Severin, M. G. and Vianello, E. J. Am. Chem. Soc. 118 (1996) 7190.

10. Savéant, J. M. J. Am. Chem. Soc. 114 (1992) 10595.

11. Andrieux. C. P., Blocman, C., Dumas-Bouchiat, J. M. and Savéant, J. M. J. Am. Chem. Soc. 101 (1979) 3431.

12. Andrieux, C. P., Gallardo, I., Savéant, J. M. and Su, K. B. J. Am. Chem. Soc. 108 (1986) 638.

13. Andrieux, C. P., Le Gorande, A. and Savéant, J. M. J. Am. Chem. Soc. 114 (1992) 6892.

14. Matsuda, H. and Ayabe, Y. Z. Elektrochem. 59 (1955) 494.

15. Andrieux, C. P., Dumas-Bouchiat, J. M. and Savéant, J. M. J. Electroanal. Chem. 87 (1978) 39.

16. Lewis R. J. SAX's Dangerous Properties of Industrial Materials, 9th ed., Van Nostrand Reinhold, New York 1996, p. 1080.

17. Pletcher, D. and Slevin, L. J. Chem. Soc., Perkin Trans. 2 (1995) 2005.

18. Gul'tyai, V. P., Rubinskaya, T. Ya. and Korotaeva, L. M. Bull. Acad. Pol. Sci. Ser. Sci. Chem. (1982) 1499.

19. Wagenknecht, J. H., Goodin, R. D., Kinlen, P. J. and Woodard, F. E. J. Electrochem. Soc. 131 (1984) 1559.

Received October 7, 1998. 